\title{
Variability of expression in tuberous sclerosis
}

\author{
Hope Northrup, James W Wheless, Terry K Bertin, Richard Alan Lewis
}

\begin{abstract}
We present three families in whom a diagnosis of tuberous sclerosis is difficult to secure and we review published reports about similar cases. Tuberous sclerosis has been reported to affect as many as 1 in 9400 subjects in the population. The manifestations of this disease vary not only between but also within families. Currently no reliable method of prenatal diagnosis is available. For these reasons, subjects known to be at $50 \%$ risk should be assessed scrupulously to clarify their status. These cases illustrate the difficulties in the clinical diagnosis of tuberous sclerosis and further reinforce the need for a molecular method of determining whether an at risk subject has the disease.

(f Med Genet 1993;30:41-3)
\end{abstract}

Tuberous sclerosis (TSC) is an autosomal dominantly inherited disease manifesting a spectrum of specific hamartomata. Population frequency is reported from as low as 1 in $170000^{1}$ to as high as 1 in $9400 .^{2}$ Modern studies $^{2-4}$ suggest that TSC is much more common than reported in older studies ${ }^{156}$ and that many subjects are mildly affected with this disease. Additionally, both mildly affected and severely affected subjects are seen within the same family; TSC does not 'breed true' within families. ${ }^{7}$ Variable expression has been recognised as a characteristic of TSC for many years. ${ }^{58}$ Despite substantial documentation of variable expression, debate continues about the existence of subjects with the TSC genotype who have no detectable manifestations of the disease $\mathrm{e}^{89}$ and, therefore, about the extent of evaluation, management, and genetic counselling of those at risk for the disorder. We present three families with TSC that emphasise the difficulties in diagnosing TSC and discuss the possible explanations and implications for counselling. The diagnosis of TSC in all subjects described was made according to the criteria of Gomez. ${ }^{7}$

\section{Case reports}

FAMILY 1

The proband of family 1 (II.3, figure) was referred at the age of 8 years 9 months for facial angiofibromata, which had developed approximately one year previously, a shagreen patch, and a single toenail fibroma. The father $(I \cdot 1)$ was noted at the child's presentation to have facial angiofibromata, multiple cutaneous shagreen patches, ungual and subungual fibromata, hypopigmented skin macules, and an achromic patch of the retinal pigment epithelium in the left eye. This 47 year old father had polycystic kidney disease which had resulted in renal failure and required dialysis beginning four years earlier. He had never been diagnosed as having TSC. The proband's two older sisters (II.1 and II.2), aged 13 and 10, had no dermatological findings consistent with TSC on physical examination which included Wood's light examination of the skin.

The family was contacted again eight years later for participation in a TSC linkage study. On repeat physical examination and retinal examination by binocular indirect ophthalmoscopy, no signs of TSC were detected in either of the proband's sisters (then aged 21 and 18). The oldest sister (II 1 ) had a suggestion of a periungual fibroma around one fingernail, but no other stigmata suggestive of TSC. Testing for the linkage study included non-enhanced CT scan of the brain, renal ultrasound, and EKG. Sister II· 1 was found to have multiple bilateral renal cysts and multiple calcified nodules around the lateral ventricals of the brain. Therefore, she was diagnosed as having TSC. The only significant finding in the younger sister (II-2) was a single renal cyst in each kidney. The younger sister also underwent an MRI scan of the brain and an echocardiogram, but no additional features of TSC were noted.

\section{FAMILY 2}

The proband of family 2 (II 4 , figure) presented with infantile spasms at 1 month old. She was diagnosed later as having TSC because she has multiple hypopigmented macules, a shagreen patch, multiple achromic patches of the retinal pigment epithelium, seizures, and developmental delay.

Her 16 year old brother (II $\cdot 1$ ) had onset of focal seizures at approximately 18 months old. On physical examination, he had multiple hypopigmented macules, achromic patches of the retinal pigment epithelium in both retinas, and dental pitting. His development was normal and he has since received a doctorate. Both parents were evaluated (physical examination including Wood's light examination of the skin, binocular indirect ophthalmoscopic examination of the retinas, non-enhanced CT scan of the brain, renal ultrasound, and EKG) to determine which has TSC. The only positive finding noted was a mass in the upper pole of the father's left kidney identified on ultrasound. He underwent an abdominal aortogram and a left renal arteriogram. The previously noted renal lesion was not detected and the studies were interpreted as completely normal. Additional testing (echocardiogram and MRI 
Family 1

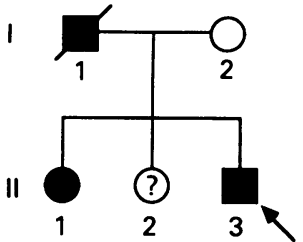

Pedigrees of the families.
Family 2

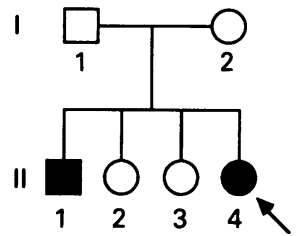

I

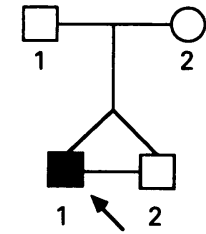

scan of the brain) was also offered to the parents but they declined.

\section{FAMILY 3}

The proband in family 3, twin A (II-1, figure), was first noted to have seizures at 15 months old. These 'staring spells' have continued. $\mathrm{He}$ was first referred to one of us (JWW) at $7 \frac{1}{2}$ years of age for an epilepsy surgery evaluation because of intractable seizures. On physical examination, he had a $5 \times 5 \mathrm{~cm}$ shagreen patch over his right lumbosacral area. No hypopigmented macules, scalp plaques, ungual fibromas, or dental pitting were noted. Further testing included binocular indirect ophthalmoscopic retinal examinations, renal ultrasound, echocardiogram, and MRI scan of the brain without and with gadolinium. He had an achromic patch of the retinal pigment epithelium in the right eye and positive findings on MRI (a 'rough' appearance to the subependymal layer of the lateral ventricles and multiple cortical abnormalities consistent with tubers).

His brother, twin B (II-2), was thought to be an identical twin. Monozygosity was confirmed by genetic marker analysis of 20 independent systems in both twins and their parents. Probability of monozygosity ranges from a minimum of 99.976 to a maximum of 99.9939. Twin B had never had seizures and on physical examination had no findings consistent with TSC. Further testing on twin B included binocular indirect ophthalmoscopic retinal examinations, renal ultrasound, echocardiogram, CT scan of the brain, and MRI scan of the brain. No findings consistent with TSC were seen. The twins both have normal development. The parents were evaluated by physical examination including Wood's light examination of the skin, binocular indirect ophthalmoscopic examination of the retinas, renal ultrasound, CT scan of the brain and MRI of the brain (mother only) and have no findings of TSC.

\section{Discussion}

Variable expression is characteristic of most dominantly inherited genetic disorders. These three families show the difficulties in the detection of minimal expression of the TSC gene even when extensive examination is performed. In family 1 , testing of internal organs determined the diagnosis of TSC in a sib at risk and led to questionable findings in a second sib at risk. In the other two families, no expression was detected in persons who most likely carry the mutated gene.
Family 1 illustrates several aspects of TSC. TSC certainly did not 'breed true'; the father and proband had obvious physical stigmata of TSC while the oldest sister had only a questionable ungual fibroma on one finger but diagnostic findings on evaluation of internal organs. Numerous published examples have few or no external stigmata of TSC but diagnostic findings on internal examination. ${ }^{10-15}$ In most of these cases, parents of affected children were evaluated with the contemporary technology then diagnosed with TSC. Transmission risks for these parents were dramatically changed. In family 1 , the oldest sister would have been considered unaffected without exhaustive testing. Detection of a single renal cyst bilaterally but no other signs of TSC in the other sister leaves us with no satisfactory answer for her transmission risk. Renal cysts are observed commonly in the population (1 to $2 \%$ ), but uncommonly in persons under 30 years of age. ${ }^{16} \mathrm{Al}-$ Gazali et $a l^{13}$ reported a similar case, the mother of a child affected with TSC who has only a single renal cyst bilaterally. Fryer $e t a l^{9}$ commented on the diagnostic dilemma of an at risk subject having only a single cyst bilaterally. Family 1 underlines the necessity of thorough diagnostic testing and also illustrates the problems which thorough testing can create.

In the second family, no evidence of TSC was found despite extensive evaluation of the parents. There are published reports of six sets of parents who have more than one child affected by TSC in which neither parent had any signs of TSC after physical examination and some evaluation of internal organs. ${ }^{49111718}$ There are two other reports, one involving a father and one a mother, in which two affected children were born to the same subject who had no signs of TSC despite extensive careful evaluation. ${ }^{19} 20$

A parent with no signs of TSC but with several affected children can be explained at least four ways: (1) two random mutations occurring within the same immediate family, (2) lack of detectable expression of the TSC gene in one of the parents, (3) gonadal mosaicism, or (4) non-paternity. Two random mutations leading to TSC occurring within the same immediate family is highly unlikely based on purported statistical data on prevalence (probability $2.25 \times 10^{-8}$ ). Lack of detectable expression of the TSC gene is one possible explanation for these cases. For example, one of us has seen a subject with two offspring by different spouses affected with neurofibromatosis type 1 (NF-1) who has only very minimal findings. ${ }^{21}$ Gonadal/somatic mosaicism has been documented as the cause of recurrence of some autosomal dominant as well as $\mathrm{X}$ linked recessive diseases. A few examples include osteogenesis imperfecta, ${ }^{22}$ pseudoachondroplasia, ${ }^{23}$ and Duchenne muscular dystrophy ${ }^{24}$ Cohn et $a l^{2}$ showed that an unaffected father who had two children with lethal osteogenesis imperfecta by different mothers was mosaic for the mutation causing the disease in lymphocytes and sperm but not in fibroblast cells. Once the TSC genes are cloned, the answer to 
this puzzle will be known. Until that time, owing to the number of well documented cases of multiple affected children with clinically investigated but unaffected parents, genetic counselling for parents of seemingly sporadic cases of TSC (even after thorough evaluation) should include a small recurrence risk.

Family 3 includes identical twin boys, one affected with TSC and the other with no detectable signs of the disease. Six sets of identical twins affected with TSC have been reported. In all cases, both twins are reported affected, usually one having more severe symptoms than the other. ${ }^{25}$ Two cases are reported in which affected subjects are related through seemingly unaffected subjects. ${ }^{1326}$ The identical twins, as well as these two cases, are examples of persons in whom we are currently unable to detect the disease. The twin cases could be the result of lack of expression of the TSC gene in the unaffected twin. This seems unlikely given the common genetic background, that is, epistatic genes that might influence expression of mutation, and the resulting expectation for similar lack of expression. Nevertheless, lack of expression cannot be ruled out since environmental or stochastic factors may play a role. Alternatively, the mutation might have occurred after the separation of the twins. This implies somatic mosaicism. Because these possibilities cannot be excluded, we cannot determine whether or not the twin without stigmata harbours the mutation.

These cases strongly caution that genetic counselling for TSC should include the caveat that the risk may be greatly reduced by negative testing of internal organs, but is not eliminated. These cases also underline the importance of finding the mutations which cause TSC and of developing a sequence based DNA diagnosis. A test in which the gene could actually be detected would eliminate the uncertainties now present and the need for expensive testing for diagnostic purposes.

We wish to thank Dr Arthur L Beaudet for help in the clinical evaluation of families 1 and 2 and Dr William A Horton for careful review of the manuscript and helpful suggestions. Testing was done in the University Clinical Research Center of Hermann Hospital through NIH Grant RR-02558. This work was supported by American Cancer Society Grant PDT-435 (HN). HN is a recipient of an American Cancer Society Junior Faculty Research Award (Grant JFRA-354). RAL is a recipient of an unrestricted grant from $\mathrm{Re}$ search to Prevent Blindness, New York.

1 Singer K. Genetic aspects of tuberous sclerosis in a Chinese population. Am f Hum Genet 1971;23:33-40.

2 Wiederholt WC, Gomez MR, Kurland LT. Incidence and prevalence of tuberous sclerois in Rochester, Minnesota, prevalence of tuberous sclerois in Rochester,
1950 through 1982. Neurology 1985;35:600-3.

3 Hunt A, Lindenbaum RH. Tuberous sclerosis: a new estimate of prevalence in the Oxford region. $₹ \mathrm{Med}$ Genet 1984;21:272-7.

4 Sampson JR, Scahill SJ, Stephenson JBP, Mann L, Connor M. Genetic aspects of tuberous sclerosis in the west of Scotland. F Med Genet 1989;26:28-31.

5 Nevin NC, Pearce WG. Diagnostic and genetical aspects of tuberous sclerosis. $\mathcal{F}$ Med Genet 1968;5:273-80.

6 Stevenson AC, Fisher OD. Frequency of epiloia in Northern Ireland. Br $\mathcal{P}$ Prev Soc Med 1956;10:134-5.

7 Gomez MR. Tuberous sclerosis. 2nd ed. New York: Raven Press, 1988.

8 Bundey S, Evans K. Tuberous sclerosis: a genetic study. $\boldsymbol{f}$ Neurol Neurosurg Psychiatry 1969;32:591-603.

9 Fryer AE, Chalmers AH, Osborne JP. The value of investigation for genetic counselling in tuberous sclerosis. $f$ igation for genetic counselin
Med Genet 1990;27:217-23.

10 Flinter RA, Neville BGR. Examining the parents of children with tuberous sclerosis. Lancet 1986;ii:1167.

11 Murphy JV, D'Souza BJ, Haughton VM. CT scans and tuberous sclerosis. $¥ A M A$ 1976;236:1115.

12 Cassidy SB, Pagon RA, Pepin M, Blumhagen JD. Family studies in tuberous sclerosis. $\mathfrak{F} A M A$ 1983;249:1302-4.

13 Al-Gazali LI, Arthur RJ, Lamb JT, et al. Diagnostic and counselling difficulties using a fully comprehensive screening protocol for families at risk for tuberous sclerosis. F Med Genet 1989;26:694-703.

14 Roach ES, Kerr J, Mendelsohn D, Laster DW, Raeside C Detection of tuberous sclerosis in parents by magnetic resonance imaging. Neurology 1991;41:262-5.

15 Webb DW, Osborne JP. Non-penetrance in tuberous sclerosis. $\mathcal{f}$ Med Genet 1991;28:417-9.

16 Becker JA, Schneider M. Simple cyst of the kidney. Semin Roentgenol 1975; X:103-11.

17 Wilson J, Carter C. Genetics of tuberose sclerosis. Lancet 1978;

18 Rott HD, Fahsold R. Tuberous sclerosis in two sibs of normal parents. Clin Genet 1991;39:306-8.

19 Michel JM, Diggle JH, Brice J, Mellor DH, Small P. Two half-siblings with tuberous sclerosis, polycystic kidneys and hypertension. Dev Med Child Neurol 1983;25:239-44.

20 Connor JM, Stephenson JBP, Hadley MDM. Non-penetrance in tuberous sclerosis. Lancet 1986;ii: 1275.

21 Riccardi VM, Lewis RA. Penetrance of von Recklinghausen neurofibromatosis: a distinction between predecessors and descendants. Am f Hum Genet 1988;42:284-9.

22 Cohn DH, Starman BJ, Blumberg B, Byers PH. Recurrence of lethal osteogenesis imperfecta due to parental mosaicism for a dominant mutation in a hum parnt mosaicism for a dominant mutation in a human type 1 collagen

23 gene (COLIAI). Am F Hum Genet 1990;46:591-601. mosaicism in pseudoachondroplasia. Am $\mathcal{f}$ Med Genet mosaicism in pse

24 Bakker E, Van Broeckhoven CH, Bonten EJ, et al. Germline mosaicism and Duchenne muscular dystrophy mutations. Nature 1987;329:554-6.

25 Gomez MR, Kuntz NL, Westmoreland BF. Tuberous sclerosis, early onset of seizures, and mental subnormality: study of discordant homozygous twins. Neurology 1982;32:604-11.

26 Baraitser M, Patton MA. Reduced penetrance in tuberous sclerosis. F Med Genet 1985;22:29-31. 